\title{
Experimental and Theoretical Studies of Wet Snow Accumulation on Inclined Cylindrical Surfaces
}

\author{
Behrouz Mohammadian (D), Mehdi Sarayloo (i), ${ }^{2}$ Ahmed Abdelaal (iD, ${ }^{3}$ Asif Raiyan, \\ Douglas K. Nims, ${ }^{2}$ and Hossein Sojoudi ${ }^{1}$ \\ ${ }^{1}$ Department of Mechanical, Industrial and Manufacturing Engineering, University of Toledo, Toledo, OH, USA \\ ${ }^{2}$ Department of Civil and Environmental Engineering, University of Toledo, Toledo, OH, USA \\ ${ }^{3}$ Department of Engineering Technology and Industrial Distribution, Texas A\&M University, College Station, TX, USA
}

Correspondence should be addressed to Hossein Sojoudi; hossein.sojoudi@utoledo.edu

Received 24 September 2019; Accepted 20 January 2020; Published 20 February 2020

Academic Editor: Jing-song Hong

Copyright (c) 2020 Behrouz Mohammadian et al. This is an open access article distributed under the Creative Commons Attribution License, which permits unrestricted use, distribution, and reproduction in any medium, provided the original work is properly cited.

\begin{abstract}
Wet snow accumulation on bridge cables and its shedding due to external phenomena such as rise in temperature, wind, and gravity is a serious threat to the safety of cars and pedestrians crossing the bridge. Commonly the accumulated snow on bridge cables is removed by external means such as mechanical removal or heat treatment which are expensive, timeconsuming, and high-risk processes and are conducted based on little or no information available regarding the actual size and shape of the accumulated snow. In addition, cleaning of cables using the mechanical methods can potentially lead to erosion of cable materials when applied over years, resulting in enhanced surface roughness and potentially increased wet snow/ice accumulation during future precipitation events, and sometimes might require replacement of cable stays, which is an extremely costly and complicated task. Optimizing the number of mechanical cleaning procedures such as chain release through predicting the shape and thickness of the accumulated snow on the cable stays reduces the cost, time, and risk associated with the process. In this study, wet snow accumulation on torsionally rigid inclined cylinders of high-density polyethylene (HDPE) has been studied experimentally and numerically. A 2-D numerical model has been developed utilizing weather data to predict the thickness and the shape of the accumulated wet snow on inclined cylindrical surfaces. Outdoor experiments were also conducted to measure the density and thickness of accumulated snow, while monitoring the weather data real time. Overall, snow density was found to be linearly increasing with an increase in wind velocity, during snow precipitation. The maximum thickness and shape of the accumulated snow on cables obtained from the numerical model were found to be in good agreement with the outdoor experimental data. This work aims to provide a mean for prediction of snow accumulation on surfaces for optimizing the efficiency of the costly and high-risk snow removal procedures.
\end{abstract}

\section{Introduction}

Atmospheric icing is referred to various processes in which water droplets in atmosphere freeze and adhere to surfaces potentially posing severe risks to the security of man-made structures $[1,2]$. For example, ice and wet snow accumulation on structures such as power transmission lines, bridge cables, wind turbine blades, and aircraft wings can reduce efficiency, cause detrimental environmental consequences, enhance safety hazards, and increase operational costs [3-7]. The cost of damages of wet snow accretion could be in the order of 100 million US dollars per storm [8]. Therefore, significant ice loads form due to particles in the air colliding with surfaces with different geometries. These particles can be liquid (usually supercooled), solid, or a mixture of water and ice. In any case, the maximum rate of icing can be determined using basic ice accretion model described in the ISO 12494 [1]. There are three types of atmospheric icing: in-cloud icing, precipitation icing, and hoar frost [5]. In-cloud icing is the conversion of supercooled liquid droplets existing in clouds 
into ice. Due to different atmospheric conditions, the process occurs in different ways. If there is no liquid layer and no runoff from the surface, the process is called dry growth and the resulting in-cloud icing is rime with droplet diameters in the range of $5-70 \mu \mathrm{m}$. Otherwise, if there is a liquid layer on the surface, the process is called wet growth and the resulting in-cloud icing is glaze with droplet diameters ranging from $70 \mu \mathrm{m}$ to even a few millimeters $[9,10]$. Glaze can also originate from the precipitation of freezing rain. Freezing rain is a type of precipitation icing, and it forms when crystals of snow melt before hitting the surface [11]. Other types of precipitation icing are wet snow and dry snow. Freezing of nucleated water droplets around tiny dust particles in clouds creates elaborate and symmetrical snow crystals. In temperatures slightly greater than zero centigrade, dry snowflakes start to melt rounding their crystalline shape and changing to wet snow [12]. Wet snow contains ice granules, liquid water, and air bubbles. The heat exchange between snow and air determines the amount of these components in the snow. Low snow density $\left(\rho<100 \mathrm{Kg} / \mathrm{m}^{3}\right)$, low liquid water content in snow ( $\mathrm{LWC}<5 \%$ ), and domination of air bubbles in volume (more than 70\%) are the results of low heat exchange between the air and the snow $[12,13]$. Hoar frost forms as a result of direct transformation of water vapor in the air to ice deposition on a surface at negative temperatures. Accretion of hoar frost on power transmission lines may result in considerable energy losses because of corona discharge; however, hoar frost has light weight and is harmless on most structures [2].

Among different types of atmospheric icing, wet snow attracted particular attention among scientists, due to its complex nature and stickiness to various surfaces [14]. Wet snow accumulation is common in areas where high snow precipitation rates occuring near the freezing point, such as Japan, Norway, Iceland, many other European countries, and even parts of the USA and Canada [2].

Wet snow accretion on structures causes two major problems. First, the extra loads added by wet snow accumulation may cause breakage of the structures. Second, it changes the shape of the structures continuously, altering aerodynamics and general functionality of the system [2]. For example, failure of power transmission lines by wet snow accumulation due to the extra loads or extra forces applied to the cables because of altered aerodynamic of the system causes loss of time and money. In addition, due to rise in temperature and external forces such as wind and gravity the blocks of accumulated wet snow may fall from structures such as bridge cables and can cause detrimental safety and operational concerns. Recently, development of coatings to prevent ice/snow accumulation and, in case of any formation, reduce their adhesion strength to surfaces has received considerable attention $[3,4,10,15]$. However, these coatings are far away from being applied to industrial surfaces due to their durability, scalability, and mechanical-robustness issues [10]. Therefore, prediction of wet snow accretion on structures to optimize snow removal procedures is of great importance.

Based on limited experiences, snow accretion on structures may occur at temperatures even as low as $-7^{\circ} \mathrm{C}$. However, there is a weak adhesion force between the surface and the snow blocks at subfreezing temperatures due to low liquid water content of snowflakes, meaning that the snow accumulation only occurs at low wind speeds $(V \leq 2 \mathrm{~m} / \mathrm{s})$ [16]. At temperatures more than zero, snow accretion may occur in any wind speed.

There are different viewpoints about the temperatures at which wet snow forms. Admirat claimed wet snow occurs only in air temperatures in the range of $0^{\circ} \mathrm{C}$ to $2^{\circ} \mathrm{C}$ [12]. Based on heat transfer calculations, Makkonen asserted that wet snow accretes in wet bulb temperatures more than zero [8], and later modified his claim in 2010 to wet bulb temperatures more than $-0.2^{\circ} \mathrm{C}$ [17]. Finstad proposed that wet snow happens for air temperatures of $-2^{\circ} \mathrm{C}<T_{a}<5^{\circ} \mathrm{C}$ and critical percent relative humidity of more than $85.1-5.3 \times T_{a}$ [18] . Due to the higher water content of wet snow in contrast to dry snow, wet snow has higher density; therefore, a longlasting wet snow event creates higher loads on structures such as power transmission lines and bridge cable stays. During our outdoor experiments, we learned that snow was sticking to surfaces when the temperature was between $-2^{\circ} \mathrm{C}$ to $5^{\circ} \mathrm{C}$. Therefore, in this work, we will be using $-2^{\circ} \mathrm{C}<T_{a}<5^{\circ} \mathrm{C}$ as an assumption for accumulation of wet snow.

Simulation of wet snow accretion on horizontal torsionally flexible cables such as power transmission lines assumes that snow accretes cylindrically around them due to their flexible nature $[8,12,14,16-20]$. However, in torsionally rigid inclined cables, the nature of wet snow accumulation in shape and size is different, and it occurs at the windward side of the cables. Szilder has recently utilized an analytical method and a numerical morphogenetic icing model to simulate snow accretions on oriented cylinders, but the work lacks experimental study in order to validate the analytical and numerical results [21]. Here, we developed a model that takes into account the orientation of the cable in determining the effective wind impact speed to obtain realtime thickness, location, and shape of wet snow accumulation on torsionally rigid inclined cylinders. We also developed and conducted extensive outdoor experiments to understand impact of snow precipitation parameters on its density and also to verify the shape and thickness of accumulated snow on surfaces, obtained from the numerical studies.

\section{Materials and Methods}

2.1. Theoretical Section. We study the snow accretion model in order to obtain real-time thickness, location, and shape of the accumulated snow on the cables. Makkonen and Wichura suggested that the intensity of snow accretion load on a powerline cable is a function of observed visibility $V_{m}$ [17].

However, most of the wet snow accretion models are based on a basic ice accretion equation, which is described in the ISO 12494 [1] as

$$
\frac{\mathrm{d} M}{\mathrm{~d} t}=\alpha_{1} \alpha_{2} \alpha_{3} w|\vec{V}| A,
$$

where $(\mathrm{d} M / \mathrm{d} t)(\mathrm{kg} / \mathrm{s})$ is the mass rate of wet snow accumulation; $\alpha_{1}, \alpha_{2}$, and $\alpha_{3}$ are collision, sticking, and accretion 
correction factors, respectively, which vary between 0 and 1 ; $w$ is the mass concentration of snow in air $\left(\mathrm{kg} / \mathrm{m}^{3}\right) ; A\left(\mathrm{~m}^{2}\right)$ is the cross-sectional area of the object perpendicular to the direction of snowflake impact velocity vector; and $\vec{V}(\mathrm{~m} / \mathrm{s})$ is the impact velocity of snowflakes with respect to the object, which is the vector sum of the terminal velocity of the snowflakes, $\overrightarrow{v_{s}}(\mathrm{~m} / \mathrm{s})$ and wind speed $\vec{U}(\mathrm{~m} / \mathrm{s})$ :

$$
|\vec{V}|=\sqrt{\left|\vec{v}_{s}\right|^{2}+|\vec{U}|^{2}}
$$

Based on the study of Barthazy and Schefold, the terminal velocity of snowflakes is in the range of $1 \mathrm{~m} / \mathrm{s}$ to $2 \mathrm{~m} / \mathrm{s}$ [22].

The snow particles which are moving towards an object will not necessarily hit the object (Figure 1(a)). Collision efficiency $\left(\alpha_{1}\right)$ is the proportion of the flux density of the particles that hit the object to the maximum flux density of the particles. Collision efficiency does strongly depend on the flow field around the object; in addition, drag and inertia forces are determining factors of the trajectory of the object. Therefore, $\alpha_{1}$ depends on the geometry of the object and also on the size, density, and velocity of the impacting snow particles. Reynolds number $(\mathrm{Re})$ and Stokes number $(S t)$ are the momentous dimensionless numbers in determining the collision efficiency of particles moving in a continuous medium towards an object. Re is the proportion of the inertia forces to the viscous forces, and $S t$ is the ratio of the characteristic time of the particles to the characteristic time of the flow. The Re and St numbers are as follows:

$$
\begin{aligned}
& \operatorname{Re}=\frac{\rho_{a} d_{p}|\vec{U}|}{\mu}, \\
& S t=\frac{t_{0}}{(D / 2|\vec{U}|)}=\frac{\left(\rho_{p} d_{p}^{2} / 18 \mu\right)}{(D / 2|\vec{U}|)}=\frac{\rho_{p} d_{p}^{2}|\vec{U}|}{9 \mu D},
\end{aligned}
$$

where $\rho_{a}\left(\mathrm{~kg} / \mathrm{m}^{3}\right)$ and $\rho_{p}\left(\mathrm{~kg} / \mathrm{m}^{3}\right)$ are the air and snow particles density, respectively; $D(\mathrm{~m})$ is the diameter of the cables; $d_{p}(\mathrm{~m})$ is the diameter of the snow particles; and $\mu$ (pa.s) is the dynamic viscosity of the medium environment, which is air in this study.

Several investigations have been done on collision efficiency of different types of atmospheric icing on objects with different geometries such as cylinder [23-26], stranded power transmission lines [27], and airfoils $[28,29]$. Wakahama had studied trajectories of snow particles by photographing them when they were impinging to or rebouncing from a cylindrical surface [30]. It was found that trajectories of the snowflakes are very straight and the snowflakes do not follow the streamlines around the object. Although, when the density or the size of the snowflakes decreases, the snowflakes do not go through straight lines and some of them pass through the objects. In this regard, Langmuir and Blodgett have studied the impingement characteristics of cloud and spray droplets on circular cylinders [31]. Finstad et al. had used an improved drag coefficient formulation and had revised Langmuir and Blodgett's numerical study on trajectory of water droplets around an infinitely long circular cylinder. They have assumed that the flow around the cylinder is potential flow [23]. However, depending on
$\operatorname{Re}_{D}$ (Reynolds number based on the cylinder diameter, $D$ ), the potential flow field about an object can be different from the real case. Different $\operatorname{Re}_{D}$ values create different flow patterns about an object. At high $\mathrm{Re}_{D}$, the boundary layer around the cylinder is thin, and it would not greatly affect the trajectory of the particles; however, the created wake has more effect on the trajectory of the particles. At low $\operatorname{Re}_{D}$, the boundary layer grows and has significant effect on the trajectory of the particles, and the potential flow assumption is not valid anymore.

In this study, a 2-D numerical study of the collision efficiency of snow particles is done using Fluent software. Snow particles are assumed to move in a continuous medium of air towards an infinitely long circular cylinder. Because of this assumption, circle is chosen as the shape of the object, to which particles are colliding to. The cylinder diameters of $D=2 \mathrm{~cm}$, $10 \mathrm{~cm}, 15 \mathrm{~cm}, 20 \mathrm{~cm}$, and $30 \mathrm{~cm}$ are considered in the simulations. The snow particles are assumed as spherical particles, and the drag forces applied to them are based on the spherical drag law. Two different densities of $\rho_{p}=170 \mathrm{~kg} / \mathrm{m}^{3}$ and $400 \mathrm{~kg} / \mathrm{m}^{3}$ are considered for the snow particles. The diameter of snow particles typically varies in the range of $d_{p}=0.5 \mathrm{~mm}$ to $5 \mathrm{~mm}$ [32]. Here, the diameter of the snow particles are assumed to be $d_{p}=1 \mathrm{~mm}$ and $3 \mathrm{~mm}$. Using the realizable $\kappa-\varepsilon$ turbulence model, continuity and Navier-Stokes equations are solved to find velocity field and the air streamlines around the cables. The continuity and Navier-Stokes equations are depicted in the general form of the following differential equation $[33,34]$ :

$$
\frac{\partial \rho \phi}{\partial t}+\nabla\left(\rho \vec{U} \phi-\Gamma_{\phi} \nabla \phi\right)=S_{\phi}
$$

where $\vec{U}$ is the velocity vector of the flow. $\phi, \Gamma_{\phi}$, and $S_{\phi}$ are the dependent variable, diffusion coefficient, and the source term, respectively, which are mentioned in Supporting Information (Table S1). In order to solve continuity and momentum equations, boundary conditions of the computational domain must be determined. The inlet is assumed as the velocity inlet; the outlet is assumed as the pressure outlet with gauge zero pressure relative to the ambient air; the upper domain is assumed as the free slip line with no pressure and velocity change; the circular cylinder is under no-slip wall boundary condition; and the lower surface is assumed to be under symmetry boundary condition (Figure 1(c)). The particles are injected to the computational domain from the inlet, and using DPM (discrete phase model), the trajectory of the particles is determined.

The equation of motion for the suspended particles in the air is

$$
\frac{\mathrm{d} \overrightarrow{V_{p}}}{\mathrm{~d} t}=f_{d}\left(\vec{U}-\overrightarrow{V_{p}}\right)+\frac{\vec{g}\left(\rho_{p}-\rho\right)}{\rho_{p}}
$$

where $f_{d}$ is as follows:

$$
f_{d}=\frac{18 \mu}{\rho_{p} d_{p}^{2}} \frac{C_{d} \operatorname{Re}_{r}}{24}
$$



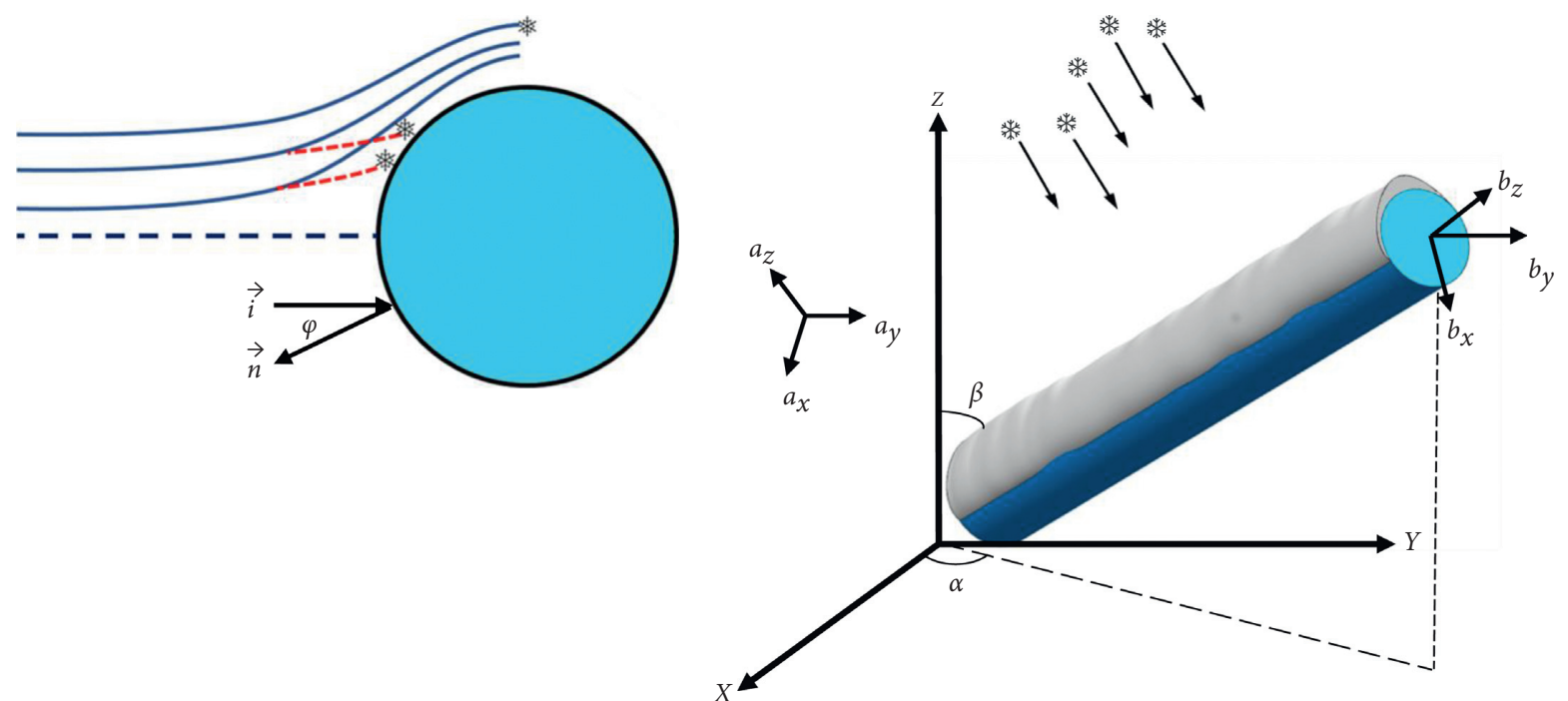

(a)

(b)

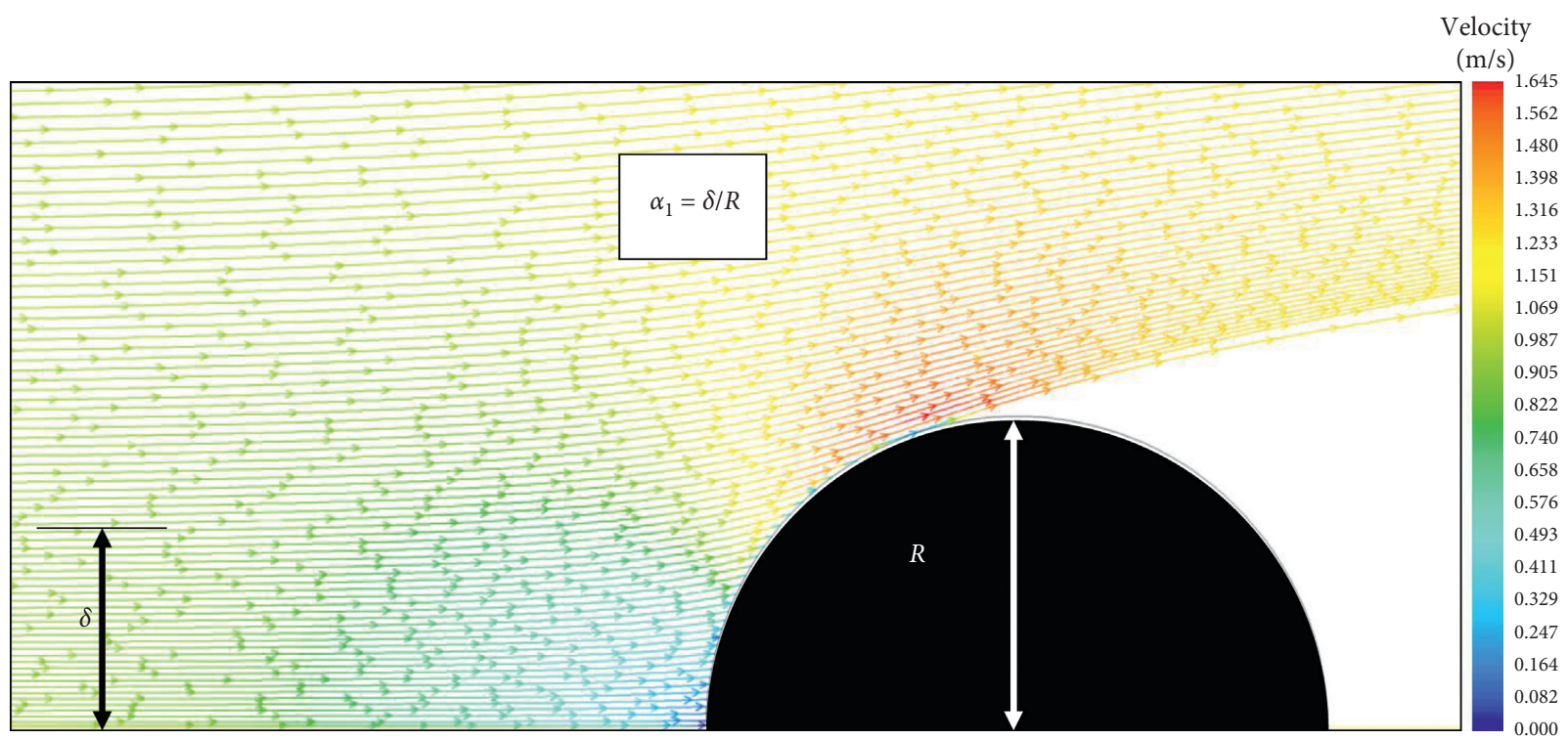

(c)

Figure 1: (a) Schematic of the snow particles in a flow around a cross section of circular cable stays. Geometry of the object, velocity, size, and shape of the snow particles are the determining factors of the route that the particles pass. (b) Schematic of snow accumulation on inclined cylindrical cable stays. A matrix is used to transform the $z$ direction (gravity direction) to centerline for modelling wet snow accumulation on torsionally rigid inclined cable stays. (c) The snow particle's velocity field for cable diameter $(D=20 \mathrm{~cm})$, diameter of snow particles $\left(d_{p}=1 \mathrm{~mm}\right)$, and density of snow particles $\left(\rho_{p}=170 \mathrm{~kg} / \mathrm{m}^{3}\right)$ with air inlet velocity $(|\vec{U}|=1 \mathrm{~m} / \mathrm{s})$.

where $\overrightarrow{V_{p}}$ is the snow particles velocity, $f_{d}\left(\vec{U}-\overrightarrow{V_{p}}\right)$ is drag force per unit mass that the snow particles are experiencing in the air. $\left(\vec{g}\left(\rho_{p}-\rho\right) / \rho_{p}\right)$ is the net weight and buoyancy forces which are applied to the particles and $\mathrm{Re}_{r}$ is the Reynolds number based on the freestream velocity relative to snow particles, $\left|\vec{U}-\overrightarrow{V_{p}}\right|$ and the diameter of the snow particles, $d_{p}$. In this study, the effects of weight and buoyancy forces are neglected.

The velocity field of the snow particles for $D=20 \mathrm{~cm}$, $d_{p}=1 \mathrm{~mm}$, and $\rho_{p}=170 \mathrm{~kg} / \mathrm{m}^{3}$ with an air inlet velocity of $|\vec{U}|=1 \mathrm{~m} / \mathrm{s}$ is shown in Figure $1(\mathrm{c})$. Also, based on the trajectory of the snow particles, obtained by Fluent simulations, $\alpha_{1}$ can be obtained as follows:

$$
\alpha_{1}=\frac{\delta}{(D / 2)}
$$

where $\delta(\mathrm{cm})$ is the $y$ coordinate of the critical particle at inlet. This is the last particle which hits the cylinder.

Validation of the collision efficiency study is done using Makkonen and Stallabrass experimental work [24]. The validation study is done for different particle diameters, cylinder diameters, and velocities. As it is shown in Table 1, there is a very good agreement between the simulation and experimental results.

Figure 2 shows the collision efficiency of the snow particles that hit the cylinder based on snow particle 
TABLE 1: Validation of the collision efficiency $\left(\alpha_{1}\right)$ study for different cable diameters $D$, snow particle diameters $\left(d_{p}\right)$, and wind velocities $(|\vec{U}|)$.

\begin{tabular}{lcccc}
\hline Cable diameter $D(\mathrm{~mm})$ & Wind velocity $|\vec{U}|(\mathrm{m} / \mathrm{s})$ & Snow particle diameters $d_{p}(\mu \mathrm{m})$ & Collision efficiency $\left(\alpha_{1}\right)[24]$ & Calculated value \\
\hline 10.24 & 20 & 13.1 & 0.46 & 0.50 \\
10.24 & 36 & 12.2 & 0.20 & 0.492 \\
31.83 & 20 & 13.1 & 0.28 & 0.557 \\
31.83 & 36 & 12.2 & 0.14 & 0.184 \\
44.40 & 20 & 13.1 & 0.18 \\
44.40 & 36 & 12.2 & 0.113 \\
\hline
\end{tabular}

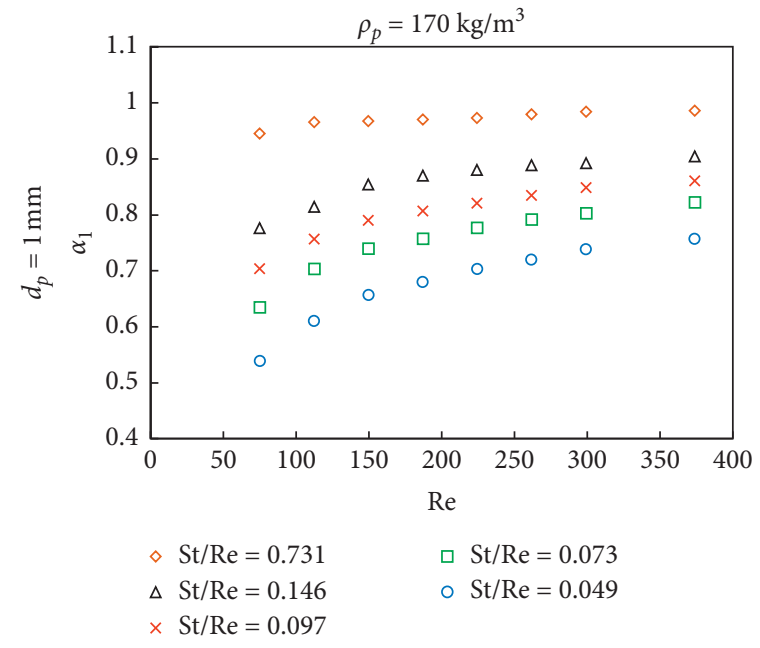

(a)

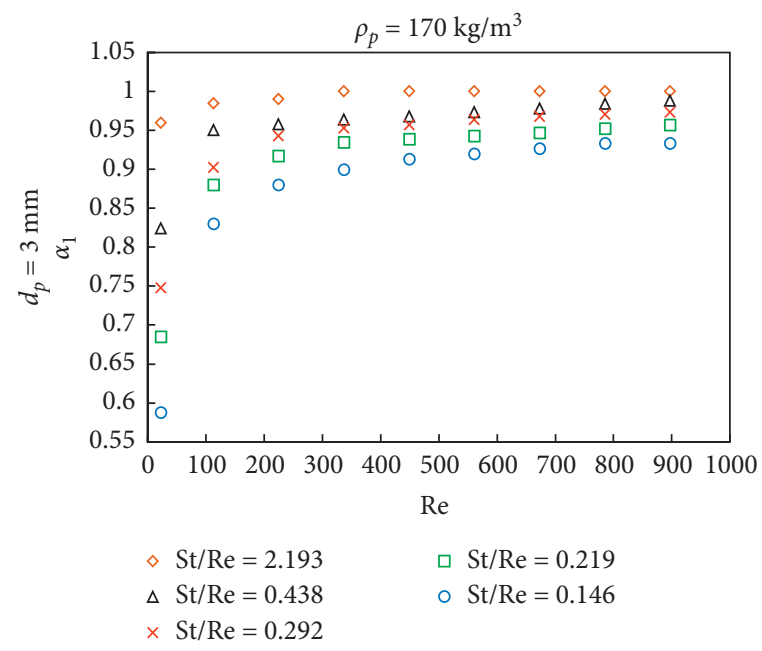

(c)

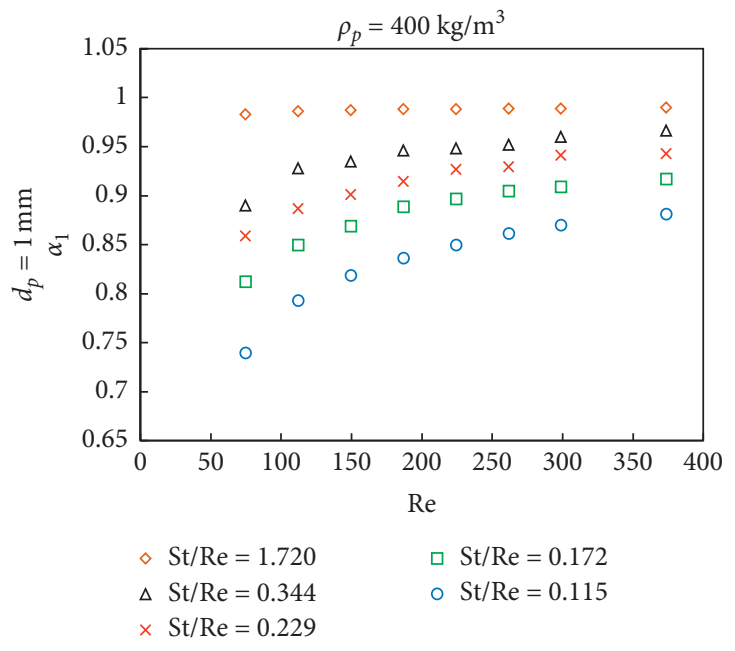

(b)

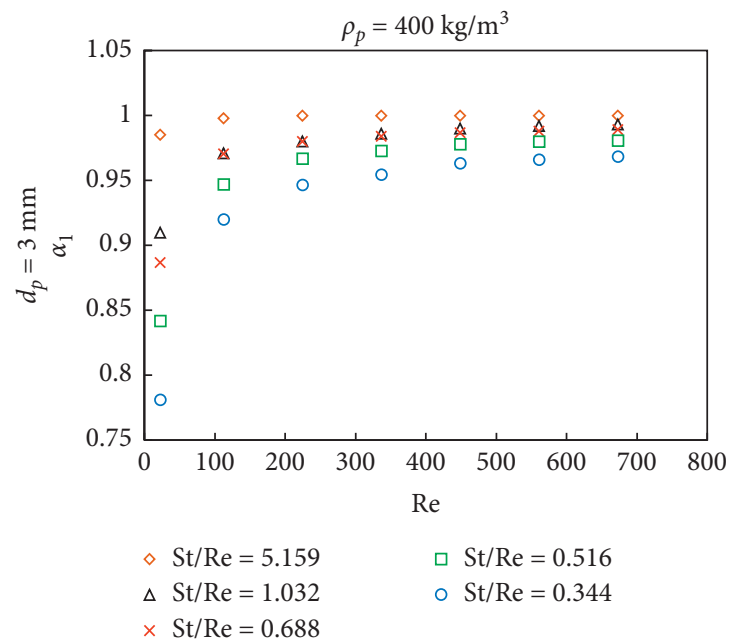

(d)

Figure 2: The collision efficiency $\left(\alpha_{1}\right)$ of the snow particles with varying snow particle diameter $\left(d_{p}\right)$ and density $\left(\rho_{p}\right)$ as a function of dimensionless Re and St $/$ Re numbers. (a) $d_{p}=1 \mathrm{~mm}, \rho_{p}=170 \mathrm{~kg} / \mathrm{m}^{3} ;$ (b) $d_{p}=1 \mathrm{~mm}, \rho_{p}=400 \mathrm{~kg} / \mathrm{m}^{3} ;$ (c) $d_{p}=3 \mathrm{~mm}, \rho_{p}=170 \mathrm{~kg} / \mathrm{m}^{3} ;(\mathrm{d})$ $d_{p}=3 \mathrm{~mm}, \rho_{p}=400 \mathrm{~kg} / \mathrm{m}^{3}$. The density, velocity, and geometry of the snow particles, besides the geometry of the cylinders, are momentous factors in determining the collision efficiency of the snow particles to the cylinders.

diameters and densities, cylinder diameters, and free stream velocities. Comparison between Figures 2(a) and 2(b) indicates that, at constant diameter of the snow particles and cylinder diameters, when the density of snow particles increases, the collision efficiency increases. Also, a comparison between Figures 2(a) and 2(c) shows that snow particles with bigger diameters and with the same density of the snow particles and the same cylinder diameters are more prone to hit the surface and have higher collision efficiencies. Therefore, it can be concluded that particles with more mass 
(diameters and/or densities) due to their higher inertia forces are more likely to hit the cylinder.

As it is shown in Figure 2(a), for a given (St/Re), which translates to a constant cylinder diameter, particles with lower $\operatorname{Re}$ (due to their lower velocity and lower inertia forces) are more inclined to pursue the air streamlines, resulting in lower collision efficiencies. Also, for a given Re number, when $(\mathrm{St} / \mathrm{Re})$ increases, which means the cylinder diameter decreases, the collision efficiency of the snow particles increases. A possible explanation for the phenomenon is that for large cylinder diameters, drag forces overcome the inertia forces and the snow particles are more prone to follow the air streamlines. Meanwhile, the air streamlines start to form sooner about a cylinder with bigger diameter than a cylinder with smaller diameter, and the particles, which are moving in the flow field toward the bigger cylinder, will be informed earlier about existence of the cylinder and will have more time to deflect and pass through the cylinder. The same trend, which is discussed here, is seen for the collision efficiency of the snow particles vs. Re and St numbers. It is believed that due to the low inertia forces compared to drag forces, particles with low velocities or densities and smaller sizes are more likely to follow the streamlines around the object, and therefore, their collision efficiency is low. In addition, particles with low St are tightly coupled with the flow, following the streamlines, and do not hit the object, whereas particles with high St do not follow the streamlines around the object and, therefore, hit the object.

Sticking efficiency $\left(\alpha_{2}\right)$ is the proportion of the flux density of the particles that stick to the object to the flux density of the particles that hit the object. Dry snowflakes rebounce from the surface when the velocity of snowflakes increases to more than $2-3 \mathrm{~m} / \mathrm{s}$, [14] where sticking efficiency essentially becomes zero. Increase in liquid water content of snowflakes results in higher amount of snow stickiness to the surfaces and increase in sticking efficiency [30].

Existing equations of sticking efficiency $\left(\alpha_{2}\right)$ are based on laboratory simulations and field observations. When particles with a higher speed hit the surface, they are less likely to stick and more likely to bounce off from it due to their higher inertia forces. For sticking efficiency,

$$
\alpha_{2}=\frac{1}{|\vec{U}|}
$$

In low wind velocities $(|\vec{U}|<1 \mathrm{~m} / \mathrm{s})$, we assume that all the particles stick to the surface and sticking efficiency becomes 1 [12].

Accretion efficiency $\left(\alpha_{3}\right)$ is the proportion of the flux density of the particles that accrete on the surface to the flux density of the particles that stick to the surface. Thermodynamic and heat transfer properties of the particles and the object are determining factors for accretion efficiency. If there is runoff from the surface due to rise of ambient temperature or sun light, accretion efficiency decreases. Accretion efficiency during wet snow accumulation is assumed to be $\alpha_{3}=1$ unless there is dripping from the surface [14].
Poots had proposed a cosine law for an analytical solution of a nonlinear wet snow accretion on surfaces. In some literature, accretion efficiency is used as a multiplication of the three abovementioned efficiencies [35]. Based on Poots' model, local accretion efficiency obeys cosine law as follows:

$$
\alpha_{\text {local }}=\alpha_{1} \alpha_{2} \alpha_{3} \cos (\varphi)
$$

where $\varphi$ is the angle between the trajectory of the particles and the vector normal to the surface; when wet snow trajectory is at the same direction of normal to the surface, maximum accumulation occurs. At any point on the surface, the mass balance analysis gives the following relation:

$$
\rho_{s} \frac{\mathrm{d} \delta}{\mathrm{d} t}=-\alpha_{1} \alpha_{2} \alpha_{3} \cos (\varphi) w|\vec{V}| A(\vec{i} \cdot \vec{n})=\alpha_{1} \alpha_{2} \alpha_{3} \cos ^{2}(\varphi) w|\vec{V}| A,
$$

and as it is shown in Figure 1(a), $\vec{i}$ is a unit vector in the $x$ direction (East) and the incremental collision point inclined at angle $((\pi / 2)-\varphi)$ to the $x$-axis, and $\vec{n}$ is the unit vector normal to the surface $[35,36]$.

Snow thickness in time $(t)$ becomes

$$
\delta=\alpha_{1} \alpha_{2} \alpha_{3} \cos ^{2}(\varphi) w|\vec{V}| A \times \frac{t}{\rho_{s}} .
$$

In order to obtain normal velocity to the surface, it is convenient to convert $x-y-z$ coordinate system to a new coordinate system attached to the inclined cable as shown in Figure 1(b).

Using two transformation matrices of rotation around $y$ axis and rotation around $z$-axis, velocities get converted to normal to the surface and parallel to the surface:

$$
\begin{aligned}
\vec{V}_{\text {new }} & =\left[\begin{array}{c}
V_{x \text { new }} \\
V_{y \text { new }} \\
V_{z \text { new }}
\end{array}\right]=R_{y z}\left[\begin{array}{c}
V_{x} \\
V_{y} \\
V_{z}
\end{array}\right], \\
R_{y z} & =\left[\begin{array}{ccc}
\cos (\beta) & 0 & -\sin (\beta) \\
0 & 1 & 0 \\
\sin (\beta) & 0 & \cos (\beta)
\end{array}\right]\left[\begin{array}{ccc}
\cos (\alpha) & \sin (\alpha) & 0 \\
-\sin (\alpha) & \cos (\alpha) & 0 \\
0 & 0 & 1
\end{array}\right] .
\end{aligned}
$$

In regular weather stations, there is no opportunity to measure the liquid water content of wet snow; however, prediction of liquid water content based on other meteorological data is possible. Admirat had supposed that the liquid water content of wet snow is a function of precipitation intensity at the ground and terminal velocity of snowflakes [12]:

$$
w=\frac{P}{3.6 \times 10^{3} \times\left|\vec{v}_{s}\right|},
$$

where $P$ is the precipitation rate at the ground in $\mathrm{mm} / \mathrm{h}$ of water equivalent and $v_{s}$ is the terminal velocity of snow in $\mathrm{m} / \mathrm{s}$.

One of the most important parameters that affect the accretion of snow on cables is density. There are different 
models to estimate wet snow density based on wind speed $[8,12,16-18]$. In addition, some researchers studied the effect of snow crystal size and/or snow fall speed on accreted snow density [37-40]. Local weather data such as wind velocity, temperature, and humidity affect snow density. In order to have a good estimation of snow thickness on cables, measurement of snow density has a significant importance due to its considerable impact of the thickness and shape of the accumulated wet snow. To this end, we conducted outdoor experiments to study the effects of wind velocity and temperature on snow density, as will be discussed in the next section.

Here, our model uses available weather data such as wind direction and magnitude, precipitation rate, and temperature and some geometrical data such as inclination and diameter of the cables for real-time prediction of thickness, location, and shape of the accumulated snow on bridge cables.

\subsection{Experimental Section}

2.2.1. Snow Density Measurement. Figure 3(c) shows a setup for measuring snow density consisted of three steel plates placed at the outdoor experimental field. The weights of the plates were measured by a digital analytical balance scale (U.S. Solid, USS-DBS8) accurately (repeatability of $\pm 0.1 \mathrm{mg}$ ). Plate A was placed on a $45^{\circ}$ inclined stage facing northwest with an angle of $40^{\circ}$ from the north, plate $B$ was placed on a $45^{\circ}$ inclined stage facing southwest with an angle of $40^{\circ}$ from south, and plate $\mathrm{C}$ was placed horizontally. To obtain more accurate snow densities in every snow event, we waited until a thick layer of snow covered the whole area of the plates (Figure 3(d)). It generally takes few hours before a considerably thick snow layer accumulates for conducting density measurements. The thickness of snow was measured at nine different spots on each plate using a digital caliper and was averaged. Then, the weight of the plate with accumulated snow was measured. From the average thickness and the weight of the snow, the density of the snow was calculated. The weather data (temperature, wind speed, wind direction, and solar radiation) were measured by using an Ambient Weather WS-2902 Professional Weather Station installed 10 feet far from the plates in a 6-feet height. The wind velocity is reported by the weather station every 5 minutes. The reported velocity is equal to the average wind velocity during these 5 minutes. Since the weather station was not designed to measure the frozen precipitation like snow, a manual springfield rain/snow gauge was used during the events as well. The precipitation was also monitored through the closest weather station in weather underground network to verify our measurements.

2.2.2. Snow Thickness Measurement. A high-density polyethylene (HDPE) bridge cable stay sample with a diameter of $D=10 \mathrm{~cm}$ was placed $31^{\circ}$ inclined with horizontal plane facing north (Figure 3(a)). As it is shown in Figure 3(b), realtime monitoring of the shape and the thickness of accumulated snow on the cables is done by using an FDT camera with the $4 \mathrm{x}$ optical zoom. The thickness of snow accumulated on the HDPE cable was measured at nine different spots as shown in Figure 3(e) using a digital caliper. This way of measurement was appropriate to have a better understanding of not only the thickness but also the shape of accumulation around the cable stay and for comparing it with cross section images of the accumulated snow obtained from the outdoor experiments (Figure 3(f)).

\section{Results and Discussion}

First, we conducted outdoor experiments to measure the density of the accumulated snow on plates and used the measured density values to simulate the accumulation of wet snow on inclined torsionally rigid cables. Then, we compared the simulation results with measured accumulated snow thicknesses and shapes on the cables.

The normal velocity of snowflakes caused compression of snow layers, while the velocity components of snowflakes parallel to the plates did not affect the snow density. By assuming the snowflakes' average falling speed of $1.7 \mathrm{~m} / \mathrm{s}$ [41] and knowing the wind speed and the inclination of the plates, the normal velocity of snowflakes to the plate is calculated using the transformation matrix. Snow density plot versus normal velocity of snowflakes is depicted in Figure 4. The amount of liquid water in the snowpack determines the wetness of the snowpack. The liquid water content in wet snow is generally affected by the temperature, and it determines the adhesion strength of snow to surfaces. During the experiments, we observed when the ambient temperature is more than $-2^{\circ} \mathrm{C}$, snowflakes tend to stick to the vertical structures. Therefore, we assumed that wet snow occurs in temperatures more than $-2^{\circ} \mathrm{C}$. Based on this assumption, three events were wet snow events, and the rest of them were dry snow events. The fitted linear trends of all the snow events have positive slope which means in higher normal velocities, more force is applied to the upper most layer of snow and snow layers compress better, resulting enhanced density in snow. However, this trend is different for dry snow events vs. wet snow events. As it can be seen in Figure 4, the variation of dry snow densities was not very large unlike the wet snow densities, and the wet snow density is more sensitive to normal velocity when compared to the dry snow. In wet snow events, due to the higher weight of snowflakes, snow blocks compress more efficiently and the trendlines in density vs. normal velocity of the wet snow become steeper.

Besides the normal velocity, ambient temperature and humidity are other determining factors of snow density. These parameters affect the heat transfer between snow particles and air. When the heat transfer between the air and the snow particles increases, the liquid water content (LWC) of snow increases. Since water density is more than air and graupel (the basic elements of snow), LWC of snow has a huge effect on snow density. In other words, higher LWC would translate to higher density. For instance, the highest density between our experiments was measured for an event with the average air temperature of $0.7^{\circ} \mathrm{C}$, which caused significant amount of melting in snowflakes both 


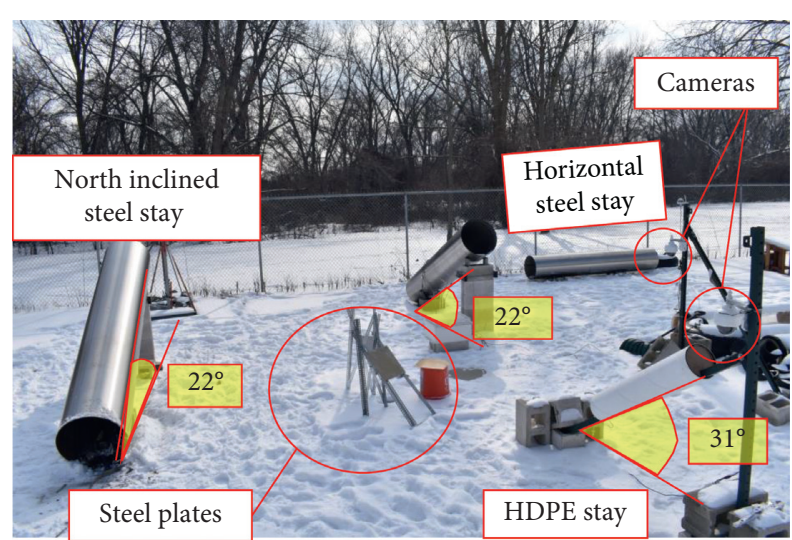

(a)

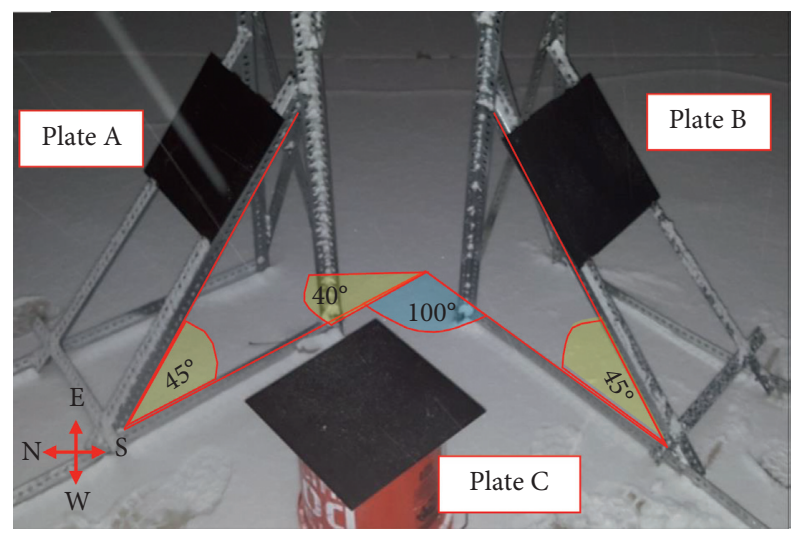

(c)

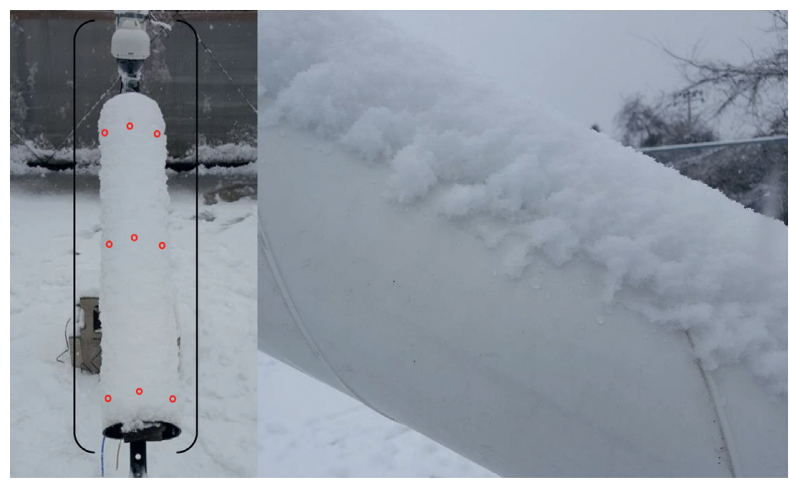

(e)

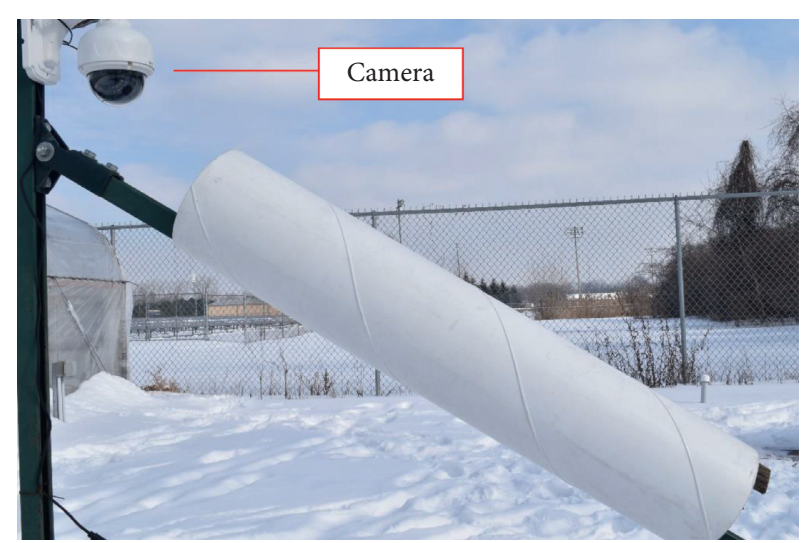

(b)

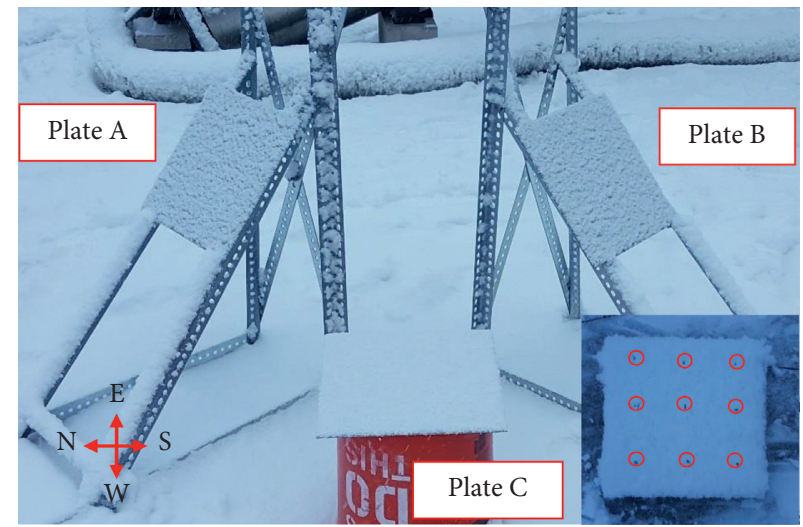

(d)

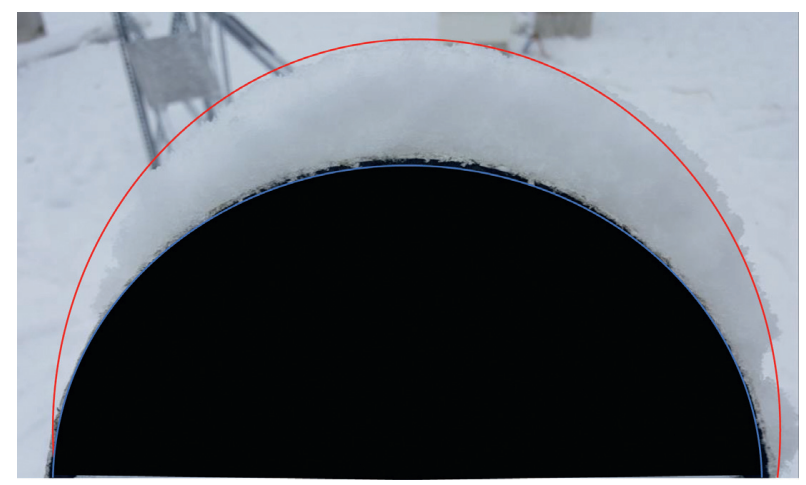

(f)

Figure 3: (a) Outdoor experimental setup to measure snow accumulation on high-density polyethylene (HDPE) and stainless-steel cable stays. (b) Close-up photo of a HDPE cable showing a camera. (c, d) Snow density measurement setup which contains two inclined plates and one horizontal plate to study the effect of inclination on snow density before and after accumulations, respectively. (e) Snow thickness values were measured on nine locations (red spots). (f) Image of the cable cross section showing snow accumulation in a peripheral shape.

during the snow fall and after accumulation. This density change affects thickness of accumulated snow on cables. As it is shown in supporting information Video S1, after 9 AM, the temperature rise results in an increase in the density of the accumulated wet snow, and as a result of better compression of snow layers, snow thickness becomes lower.

As it is shown in supporting information Figures S1(a) and $S 1(b)$, the orientation and the shape of accumulated snow obtained from the simulations of two different events are in good agreement with the deposited snow location and profile which were observed during the events. In torsionally flexible cables such as power transmission lines, snow accumulates like a cylindrical sleeve around the cables; however, in torsionally rigid cables, snow accretes peripherally on windward side of the cables. Also, as it is shown in Figure 5, we have compared the shapes of deposited snow with simulation results for event 4 . The direction and the 


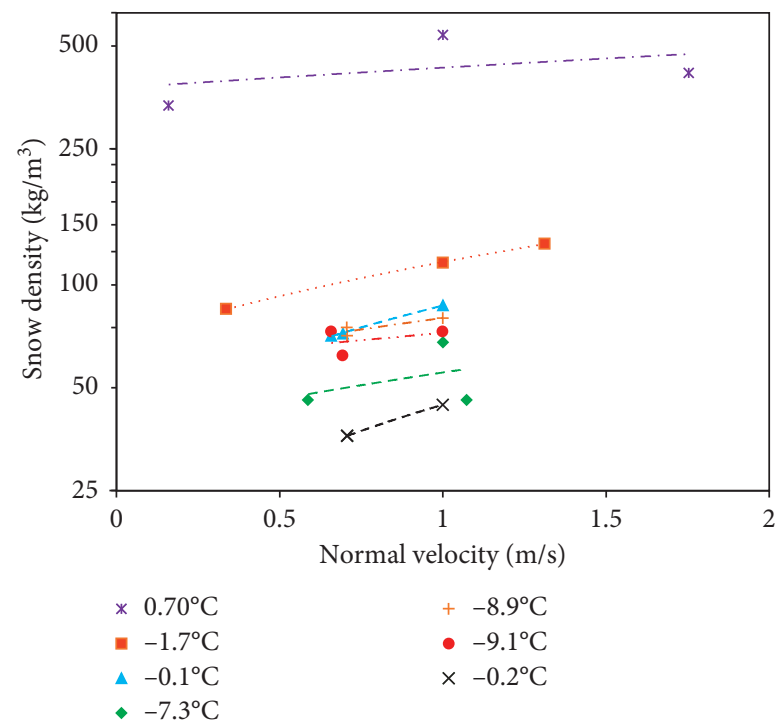

FIGURE 4: Snow density measured during different events as a function of wind velocity normal to the surface and precipitation temperature. In higher wind velocities, snow layers compress more effectively and snow density increases. Temperature and humidity are other factors that affect snow density.
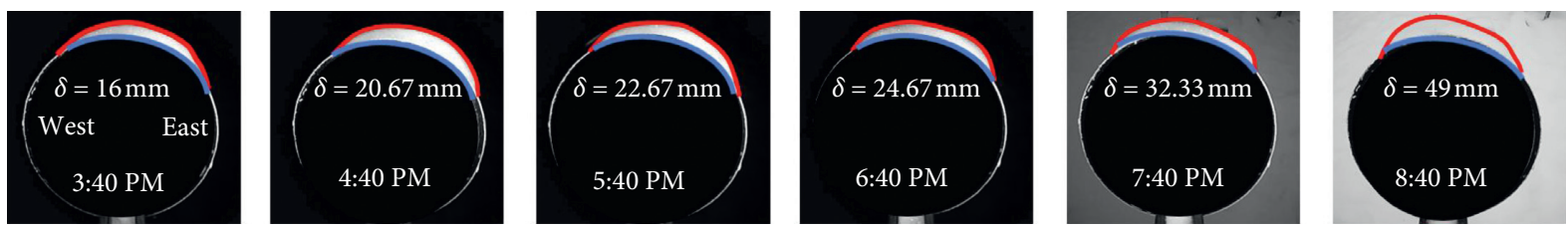

(a)
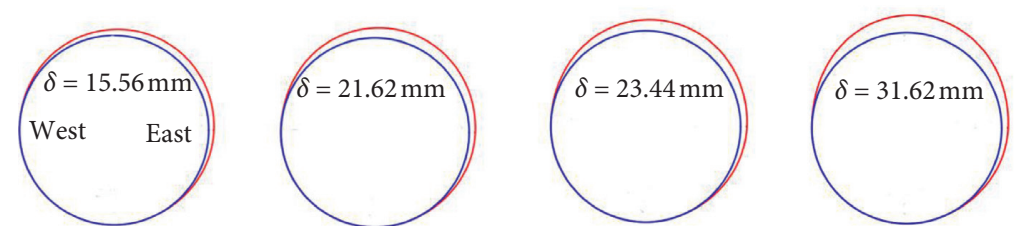

(b)
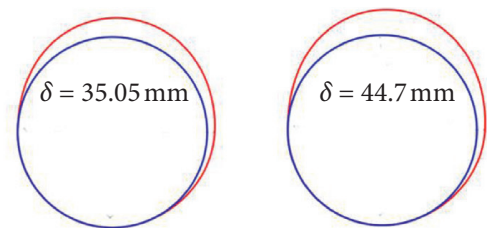

Figure 5: (a) Snow accumulation on cable stays progressively showing an increase in the thickness of the accumulated snow from left to right. (b) Simulation results of wet snow accumulation on cable stays. Diameter of the cables in these experimental and simulation studies is $D=20 \mathrm{~cm}$.

maximum thickness of accumulated snow are in good agreement with experiments. In addition, it is seen that snow blocks fall from two sides of the cable to the ground. A potential explanation for this phenomenon is re-bouncing of the snowflakes far away from the stagnation area of the cable, due to their lower stickiness capability. Also, shedding of snow from the cable sides can be another reason for the phenomenon. Shedding of snow from overhead structures can be due to the wind force, melting, or presence of heavy blocks of snow, and their failure by gravity.

The thickness of the accumulated wet snow on the cables is obtained by a 2-D numerical method. Also, in order to convert $x-y-z$ coordinate to an appropriate one, a transformation matrix is used. Table 2 shows a comparison between the snow maximum thickness on cables obtained by simulations and outdoor experiments. This table includes the results regarding 5 major snow events in Toledo, Ohio area. The maximum thickness of accumulated snow on the cables is in good agreement with measured values during the events.

The average temperature and measured density during the events are included in Table 2. In this study, for every event, the snow density is considered as a constant. But, in the course of the events, the air temperature changes and this changes the snow pack density as well. For example, for event, 2 higher amounts of density after temperature rise result in lower accumulated snow thickness which increases the error of the simulations. Therefore, constant density assumption may increase error, and real-time measurement of snow density might improve the accuracy of simulation results. 
TABLe 2: Comparison of the maximum snow thickness obtained from the experiments and simulations for different events.

\begin{tabular}{|c|c|c|c|c|c|c|c|c|c|c|c|c|c|c|}
\hline & \multicolumn{3}{|c|}{ Event 1} & \multicolumn{2}{|c|}{ Event 2} & \multicolumn{2}{|c|}{ Event 3} & \multicolumn{6}{|c|}{ Event 4} & \multirow{2}{*}{$\begin{array}{c}\text { Event } 5 \\
44.6\end{array}$} \\
\hline Density $\left(\mathrm{kg} / \mathrm{m}^{3}\right)$ & & 116.4 & & & & 67 & & & & 79 & & & & \\
\hline Real time & $10: 10$ & $11: 10$ & $12: 10$ & 7 & 8 & $8: 40$ & $9: 40$ & $3: 40$ & $4: 40$ & $5: 40$ & $6: 40$ & $7: 40$ & $8: 40$ & $23: 10$ \\
\hline Temperature $\left({ }^{\circ}\right)$ & -1.78 & -1.78 & -1.31 & -0.31 & -0.14 & -7.4 & -7.1 & -0.5 & -0.9 & -0.9 & -1 & -1.7 & -2 & -0.2 \\
\hline $\begin{array}{l}\text { Thickness }(\mathrm{mm}) \\
\text { Simulation results }\end{array}$ & 6.41 & 14.85 & 17.85 & 13.33 & 27.67 & 13.09 & 13.62 & 15.56 & 21.62 & 23.44 & 31.62 & 35.05 & 44.7 & 29 \\
\hline $\begin{array}{l}\text { Thickness }(\mathrm{mm}) \\
\text { Outdoor measurements }\end{array}$ & 9.9 & 17 & 17.67 & 14.33 & 25.67 & 10.33 & 14.33 & 16.00 & 20.67 & 22.67 & 24.67 & 32.33 & 49.00 & 31.33 \\
\hline Error $(\%)$ & 35 & 12 & 1 & 6 & 7 & 20 & -5 & 2 & 4 & 3 & 28 & 8 & 8 & 7 \\
\hline
\end{tabular}

Another source of errors is the long weather data reporting intervals. Weather conditions are changing continuously, and having the weather data in smaller time intervals can help consider the turbulence effects and temporary changes of weather condition. In summary, with the described model, we are able to predict the thickness and the orientation of the accumulated snow on bridge cables significantly and facilitate efficient snow removal from the bridge cables.

\section{Conclusions}

This paper deals with wet snow accumulation on inclined torsionally rigid cables. Prediction of thickness, shape, and orientation of wet snow accumulated on cables is crucial in developing optimized strategies for snow removal. In this work, we developed a numerical model proposing an incremental approach to obtain the real-time thickness and the shape of wet snow accumulated on cable stays using a transformation matrix. In addition, we conducted outdoor experiments to verify the accuracy of our numerical model. Wet snow density strongly impacts its accumulation shape and thickness on various surfaces, and it depends on weather conditions such as wind velocity, temperature, and humidity. Therefore, we conducted outdoor experiments to obtain the density of wet snow as a function of wind velocity and temperature and utilized the results of these measurements in the numerical simulations. The orientation and the maximum thickness of wet snow obtained from the model are in good agreement with the orientation and maximum thickness measured on the cables. This work aims to provide a method for predicting snow accumulation on bridge cables and in order to minimize the cost and risks associated during snow events. These insights provide inputs for the future studies on the fundamentals of the accretion of other types of atmospheric icing on surfaces with different geometries. In addition, it can be employed in designing potential passive and active mechanisms of icing repulsion from those surfaces.

\section{Data Availability}

The data used to support the findings of this study are available from the corresponding author upon request.

\section{Conflicts of Interest}

The authors declare that they have no conflicts of interest.

\section{Supplementary Materials}

Figure S1: a comparison of the shape and the thickness of accumulated snow on cable stays with simulation results for two different events. Table S1: summary of the general governing equation of the realizable $\kappa-\varepsilon$ turbulence model in order to solve the continuity and Navier-Stokes equations. Video S1: real-time snow accumulation on cable stays. (Supplementary Materials)

\section{References}

[1] ISO, Atmospheric Icing of Structures, ISO, Geneva, Switzerland, 2001.

[2] M. Farzaneh, Atmospheric Icing of Power Networks, Springer Science \& Business Media, Berlin, Germany, 2008.

[3] H. Sojoudi, G. H. McKinley, and K. K. Gleason, "Linker-free grafting of fluorinated polymeric cross-linked network bilayers for durable reduction of ice adhesion," Materials Horizons, vol. 2, no. 1, pp. 91-99, 2015.

[4] H. Sojoudi, H. Arabnejad, A. Raiyan, S. A. Shirazi, G. H. McKinley, and K. K. Gleason, "Scalable and durable polymeric icephobic and hydrate-phobic coatings," Soft Matter, vol. 14, no. 18, pp. 3443-3454, 2018.

[5] K. Kleissl and C. Georgakis, "Bridge ice accretion and de- and anti-icing systems: a review," in Proceedings of the 7th International Cable Supported Bridge Operators' Conference 2010, pp. 161-167, Zhenjiang, China, May 2010.

[6] J. Kumpf, A. Helmicki, D. K. Nims, V. Hunt, and S. Agrawal, "Automated ice inference and monitoring on the veterans' glass city skyway bridge," Journal of Bridge Engineering, vol. 17, no. 6, pp. 975-978, 2012.

[7] N. Jolin, D. Bolduc, N. Swytink-Binnema, G. Rosso, and C. Godreau, "Wind turbine blade ice accretion: a correlation with nacelle ice accretion," Cold Regions Science and Technology, vol. 157, pp. 235-241, 2019.

[8] L. Makkonen, "Estimation of wet snow accretion on structures," Cold Regions Science and Technology, vol. 17, no. 1, pp. 83-88, 1989.

[9] L. Makkonen, "Models for the growth of rime, glaze, icicles and wet snow on structures," Philosophical Transactions of the Royal Society of London. Series A: Mathematical, Physical and Engineering Sciences, vol. 358, no. 1776, pp. 2913-2939, 2000.

[10] H. Sojoudi, M. Wang, N. D. Boscher, G. H. McKinley, and K. K. Gleason, "Durable and scalable icephobic surfaces: similarities and distinctions from superhydrophobic surfaces," Soft Matter, vol. 12, no. 7, pp. 1938-1963, 2016.

[11] A. Abdelaal, M. Sarayloo, and D. Nims, "Experimental study of precipitation icing on an architectural polycarbonate open mesh," in Proceedings of the 2019 International Workshop on Atmospheric Icing of Structures, Reykjavík, Iceland, June 2019. 
[12] P. Admirat, "Wet snow accretion on overhead lines," in Atmospheric Icing of Power Networks, pp. 119-169, Springer, Berlin, Germany, 2008.

[13] B. Dalle and P. Admirat, "Wet snow accretion on overhead lines with French report of experience," Cold Regions Science and Technology, vol. 65, no. 1, pp. 43-51, 2011.

[14] B. E. Kringlebotn Nygaard, H. Ágústsson, and K. SomfalviTóth, "Modeling wet snow accretion on power lines: improvements to previous methods using 50 years of observations," Journal of Applied Meteorology and Climatology, vol. 52, no. 10, pp. 2189-2203, 2013.

[15] A. Raiyan, T. S. Mclaughlin, R. K. Annavarapu, and H. Sojoudi, "Effect of superamphiphobic macrotextures on dynamics of viscous liquid droplets," Scientific Reports, vol. 8, no. 1, p. 15344, 2018.

[16] Y. Sakamoto, "Snow accretion on overhead wires," Philosophical Transactions of the Royal Society of London. Series A: Mathematical, Physical and Engineering Sciences, vol. 358, no. 1776, pp. 2941-2970, 2000.

[17] L. Makkonen and B. Wichura, "Simulating wet snow loads on power line cables by a simple model," Cold Regions Science and Technology, vol. 61, no. 2-3, pp. 73-81, 2010.

[18] K. J. Finstad, Accreted Snow Loads, US Army Cold Regions Research and Engineering Laboratory, Hanover, NH, USA, 1998.

[19] G. Poots and P. L. I. Skelton, "Thermodynamic models of wetsnow accretion: axial growth and liquid water content on a fixed conductor," International Journal of Heat and Fluid Flow, vol. 16, no. 1, pp. 43-49, 1995.

[20] G. Poots and P. L. I. Skelton, "Simple models for wet-snow accretion on transmission lines: snow load and liquid water content," International Journal of Heat and Fluid Flow, vol. 15, no. 5, pp. 411-417, 1994.

[21] K. Szilder, "Snow accretion prediction on an inclined cable," Cold Regions Science and Technology, vol. 157, pp. 224-234, 2019.

[22] E. Barthazy and R. Schefold, "Fall velocity of snowflakes of different riming degree and crystal types," Atmospheric Research, vol. 82, no. 1-2, pp. 391-398, 2006.

[23] K. J. Finstad, E. P. Lozowski, and E. M. Gates, "A computational investigation of water droplet trajectories," Journal of Atmospheric and Oceanic Technology, vol. 5, no. 1, pp. 160170, 1988.

[24] L. Makkonen and J. R. Stallabrass, "Experiments on the cloud droplet collision efficiency of cylinders," Journal of Climate and Applied Meteorology, vol. 26, no. 10, pp. 1406-1411, 1987.

[25] B. Yoon and R. Ettema, "Droplet trajectories and icing-collision efficiencies for cylinders determined using LDV," Cold Regions Science and Technology, vol. 21, no. 4, pp. 381-397, 1993.

[26] H. R. Plumlee and R. G. Semonin, "Cloud droplet collision efficiency in electric fields," Tellus, vol. 17, no. 3, pp. 356-364, 1965.

[27] J. Zhang, L. Makkonen, and Q. He, "A 2D numerical study on the effect of conductor shape on icing collision efficiency," Cold Regions Science and Technology, vol. 143, pp. 52-58, 2017.

[28] E. P. Lozowski and M. M. Oleskiw, Computer Modeling of Time-dependent Rime Icing in the Atmosphere, Cold Regions Research and Engineering Lab, Hanover, NH, USA, 1983.

[29] J. Y. Jin and M. S. Virk, "Study of ice accretion along symmetric and asymmetric airfoils," Journal of Wind Engineering and Industrial Aerodynamics, vol. 179, pp. 240-249, 2018.
[30] G. Wakahama, "Experimental studies of snow accretion on electric lines developed in a strong wind," Natural Disaster Science, vol. 1, no. 1, pp. 21-33, 1979.

[31] I. Langmuir and K. Blodgett, A Mathematical Investigation of Water Droplet Trajectories, Vol. 10, Army Air Forces Headquarters, Washington, DC, USA, 1945.

[32] T. Skilling, "How big are "big" snowflakes?" 2006, https://www. chicagotribune.com/news/ct-xpm-2006-02-12-0602120224-story. html.

[33] ANSYS, ANSYS Fluent User's Guide, ANSYS, Canonsburg, PA, USA, 2011.

[34] S. Patankar, Numerical Heat Transfer and Fluid Flow, CRC Press, Boca Raton, FL, USA, 1980.

[35] A. Abdelaal, D. Nims, K. Jones, and H. Sojoudi, "Prediction of ice accumulation on bridge cables during freezing rain: a theoretical modeling and experimental study," Cold Regions Science and Technology, vol. 164, Article ID 102782, 2019.

[36] G. Poots, Ice and Snow Accretion on Structures, Vol. 10, Research Studies Press Ltd., Taunton, UK, 1996.

[37] M. Ishizaka, H. Motoyoshi, S. Yamaguchi, S. Nakai, T. Shiina, and K.-i. Muramoto, "Relationships between snowfall density and solid hydrometeors, based on measured size and fall speed, for snowpack modeling applications," The Cryosphere, vol. 10, no. 6, pp. 2831-2845, 2016.

[38] M. Kajikawa, "Relationship between new snow density and shape of snow crystals," Journal of the Japanese Society of Snow and Ice, vol. 51, no. 3, pp. 178-183, 1989.

[39] M. Kajikawa, H. Goto, T. Saruwatari, K. Kanaya, M. Hashimoto, and K. Kikuchi, "Studies on the characteristics of snow particles affecting new snow density," Journal of the Japanese Society of Snow and Ice, vol. 67, no. 3, pp. 213-219, 2005.

[40] B. A. Power, P. W. Summers, and J. D’Avignon, "Snow crystal forms and riming effects as related to snowfall density and general storm conditions," Journal of the Atmospheric Sciences, vol. 21, no. 3, pp. 300-305, 1964.

[41] S. E. Yuter, D. E. Kingsmill, L. B. Nance, and M. Löffler-Mang, "Observations of precipitation size and fall speed characteristics within coexisting rain and wet snow," Journal of Applied Meteorology and Climatology, vol. 45, no. 10, pp. 1450-1464, 2006. 